\title{
Research on the Construction of China's Science and Technology Innovation Service Platform Based on the Perspective of Collaborative Innovation
}

\author{
Shaogang Liao, Wendong Xie \\ School of Finance, Taxation and Public Administration, Jiangxi University of Finance and Economics, Nanchang, China \\ Email address: \\ liaoshaogang@163.com (Shaogang Liao) \\ To cite this article: \\ Shaogang Liao, Wendong Xie. Research on the Construction of China's Science and Technology Innovation Service Platform Based on the \\ Perspective of Collaborative Innovation. International Journal of Business and Economics Research. Vol. 8, No. 4, 2019, pp. 161-169. \\ doi: 10.11648/j.ijber.20190804.11
}

Received: April 8, 2019; Accepted: May 29, 2019; Published: July 1, 2019

\begin{abstract}
Collaborative innovation is a new form of national science and technology innovation. As a link and bridge for regional science and technology innovation, science and technology innovation service platform plays an important role in promoting the coordinated innovation of government, industry, universities and research institutions, and promoting the transformation and upgrading of regional industrial economic structure. This paper takes Jiangxi Province of China as an example. Through research and data statistics, it summarizes the construction achievements of Jiangxi Science and Technology Innovation Service Platform and analyzes the barriers that exist in the development process of the platform. At the same time, it summarizes and refines the successful experience of developed countries in the construction of Science and Technology Innovation Service Platform. On this basis, based on the collaborative innovation perspective of government, industry, universities and research institutions, the development path of Jiangxi science and technology innovation service platform is proposed from four aspects: Strengthening Policy Support and Perfecting Supporting Guarantee Mechanisms; Information resources co-construction and sharing and collaborative innovation; strengthening talent team construction and establishing scientific evaluation mechanism.
\end{abstract}

Keywords: Scientific and Technological Innovation, Collaborative Innovation, Industry-University-Research, Service Platform, Development Path

\section{Introduction}

Under the guidance of new technologies such as artificial intelligence, the role of technological innovation in driving regional economic development has become more and more obvious, and it has become a new engine for high-quality economic development. However, with the continuous development of science and technology, the difficulty and depth of science and technology in various fields are increasing. It is difficult for general enterprises and research institutes to rely on their own resources to achieve all innovation goals. Collaborative innovation has emerged as the times require [1]. In 2017, Premier Keqiang Li of the State Council of China made important instructions at the Innovation Conference on Industry, University and Research Cooperation. The instructions pointed out that strengthening cooperation between industry, universities and research institutes is an important support for opening up the innovation chain and promoting innovation and development. We must comprehensively and thoroughly implement the spirit of the 19th Party Congress, focus on implementing innovation-driven development strategies, and rely on "Internet + " and mass entrepreneurship, and innovation to create a collaborative innovation platform [2]. As an important part of the regional science and technology innovation system [3], the science and technology innovation service platform is an important carrier for improving the independent innovation capability of the industry and promoting the development of industrial innovation. As a developing country, China has made important contributions to the world economic construction. However, China's economic development has entered a new normal state. The 
traditional industrial structure and development forms can no longer meet China's rapid development, and the upgrading and transformation of China's economic structure is facing many difficulties. As an important grasp of implementing the strategy of innovation-driven development, the construction of science and technology innovation service platform plays an important role in improving China's science and technology innovation system, tapping its potential of science and technology resources, promoting collaborative innovation among government, industry, universities and research institutes, and forming a new pattern of "four-wheel-driven" science and technology innovation. Moreover, it can play a more effective role in leading and supporting scientific and technological innovation in driving economic development. At the same time, it is of great significance to cultivate new driving force of China's economic growth and to make China become a big and a powerful country of science and technology.

\section{Literature Review}

With the driving role of scientific and technological innovation in regional economic development becoming more and more obvious, the service platform of scientific and technological innovation, as an important carrier of scientific and technological innovation activities, has attracted the attention of scholars all over the world in recent years. In the face of fierce international scientific and technological and economic competition, building a first-class scientific and technological innovation platform is the priority choice to support innovation activities and strategic measures to achieve leapfrog development (Davila T, Eptein M. J, Shelton R, 2006) [4]. Sanjiv S. Gulshan (2011) considers the platform to be a new innovation model through which internal and external innovations are absorbed to achieve economies of scale [5]. Catherine W. Kilelu et al (2013) regards innovation platform as an intermediary agency of science and technology services, through which information and knowledge can be exchanged among innovation subjects [6]. In terms of the construction of regional science and technology innovation service platform, Sun Qing and Wang Hongqi (2010) constructed the local science and technology innovation platform system by using the system theory, analyzed the design and operation process of the local science and technology innovation platform system, and put forward the organizational guarantee mechanism, collaborative integration mechanism and innovation incentive mechanism to promote the effective operation of the local science and technology innovation platform system [7]. In response to the problems existing in the construction and operation of the Chinese platform, Wang Ruimin, and Zhang Wenjun (2010) used the "system failure" theory to propose a general model framework for the construction of integrated platforms, and from the three aspects of preventing interaction failure, infrastructure failure and system failure, respectively [8]. The countermeasures for improving the operational efficiency of the public technology service platform were put forward. Li Zenghui, Wang Xiuting, et al. (2012) combined with the objective reality of China's key industry development, constructed a theoretical model of industrial technology innovation service platform that is in line with China's national conditions and integrated innovation resources to achieve open and efficient resources [9]. Li Yanping and Wu Shaotang (2012) assessed the current situation of public innovation platform construction in strategic emerging industries in Wuhan from the perspective of innovation service demand of strategic emerging industries development, and put forward policy suggestions on improving innovation service support chain and building industry public innovation service platform [10].

In summary, in view of the construction of science and technology innovation service platform, scholars from different countries put forward different suggestions from different angles, which laid a theoretical foundation for the construction of science and technology innovation service platform based on the perspective of collaborative innovation, but there are also shortcomings. Firstly, most scholars focus on how to improve the economic efficiency, operation mechanism and operation mechanism of science and technology innovation service platform. Secondly, few scholars have studied the construction of service platform for scientific and technological innovation from the perspective of collaborative innovation. The scientific and technological innovation activities need multi-stakeholders to cooperate with each other in order to achieve the highest benefits. Therefore, the construction of service platform for scientific and technological innovation based on the perspective of collaborative innovation is of great significance.

\section{Overview of China's S\&T Innovation Service Platform Construction--Taking Jiangxi Province as an Example}

Since the four ministries and commissions jointly promulgated the "2004-2010 National Science and Technology Basic Conditions Platform Construction Outline" in 2004, all provinces and cities across the country have responded positively and established corresponding conditions platforms. For example, Beijing initiated the construction of the "Capital Science and Technology Condition Platform", Zhejiang Province launched the "Zhejiang Province Science and Technology Public Service Platform", and Shanghai launched the "Shanghai R\&D Public Service Platform". In short, in order to drive the improvement of regional scientific and technological innovation, both the country and the provinces and cities have accelerated the construction of science and technology innovation service platforms. As an underdeveloped region in central China, Jiangxi Province has a relatively backward science and technology foundation, and the construction of a scientific and technological innovation service platform started late, but it has developed rapidly [11]. Since the establishment of the relevant technology platform in 2004, it has begun to take shape. At present, Jiangxi Province has established key 
laboratories, engineering technology centers, Engineering Research centers, engineering laboratories, large-scale scientific instruments sharing service platforms, scientific and Technological Literature Sharing Service platforms, natural science and technology resources and scientific data sharing platforms around the key areas of upgrading traditional industries such as new generation information technology, food and medicine, photoelectricity, plant biology, rare earth, etc. It plays an important role in meeting the technological needs of enterprises, breaking through key technologies and promoting the industrialization of scientific. It plays an important role in meeting the technological needs of enterprises, solving the technological problems of industries, breaking through key technologies and promoting the industrialization of scientific and technological achievements [12].

In recent years, Jiangxi Province has insisted on taking the outline of national science and technology infrastructure platform construction as the guidance, and through the continuous integration of science and technology resources, talents, funds, equipment and other scientific and technological innovation resources, effectively accelerated the pace of the construction of science and technology innovation service platform. Up to now, there are 8 National Engineering (technology) research centers, 346 provincial engineering (technology) research centers, 5 state-level key laboratories and 181 provincial key laboratories in Jiangxi Province. There are 3024 technology contracts signed in the whole year, and the turnover of technology market contracts is 11.58 billion yuan. The State Key Laboratory of Nuclear Resources and Environment of East China University of Technology, Jiangzhong Group Scientific Research Center, Jiangxi Industrial Technology Innovation and Development Center of Chinese Academy of Sciences, Jiangxi Beidou Applied Research Institute and other research centers have been established, which has added new strength to Jiangxi's scientific and technological innovation system. Supported by various innovative service platforms and innovative carriers, Jiangxi Province has also made significant breakthroughs in the field of science and technology. In 2017, there are 104 science and technology awards in Jiangxi Province, including 20 Provincial Natural Science awards, 7 provincial technology invention awards and 77 provincial science and technology progress awards. At present, Jiangxi Science and Technology Innovation Service Platform mainly provides science and technology literature, science and technology consultation, analysis and testing, science and technology evaluation, intellectual property rights, entrepreneurship incubation, science and technology training, information network and other related services. Its purpose is to make full use of modern information technology and network technology, and to establish a network of nine databases and five systems of public service carriers of science and technology innovation [13]. However, as the construction of Jiangxi science and technology innovation service platform is still in the exploratory stage, the operation mechanism and mode of the platform is still in the perfect stage, there are barriers to the exchange and cooperation between industry, University and research, inadequate sharing of scientific and technological resources, shortage of scientific and technological funds and talents, and other problems are increasingly apparent, resulting in the weak comprehensive operation capacity of the platform, and the role of science and technology innovation service platform has not yet been maximized.

\section{Barriers to Development: Constraints on the Construction of S\&T Innovation Service Platform in Jiangxi Province}

After a long period of hard work, the construction of Jiangxi Science and Technology Innovation Service Platform has accumulated a certain foundation. However, in the increasingly fierce competition in science and technology, there is still a certain gap compared with the construction of science and technology innovation service platforms in developed regions of China. There are still some outstanding problems compared to the implementation of innovation-driven development strategies and the need to promote the construction of innovative provinces.

\subsection{The Basic Conditions of Platform Construction Are Weak, and the Innovation Environment Needs to Be Improved Urgently}

The construction and development of the science and technology innovation service platform is inseparable from the improvement of the technological innovation environment in its region. As an underdeveloped region in central China, Jiangxi Province's overall economic strength is not as good as that of neighboring provinces and cities, especially in the tertiary industry. According to the statistics of Jiangxi Province in 2016 (as shown in Figure 1). In the whole year of Jiangxi Province, the gross domestic product (GDP) reached $1,836.44$ billion yuan, an increase of $9.0 \%$ over the previous year. The total number ranked the 17th in the country. Among them, the added value of the primary industry was 190.45 billion yuan, an increase of $4.1 \%$; the added value of the secondary industry was 903.21 billion yuan, an increase of $8.5 \%$; the added value of the tertiary industry was 742.78 billion yuan, an increase of $11.0 \%$. In terms of industrial structure, the proportion of the three-industry structure was $10.4 \%, 49.2 \%$, and $40.4 \%$, respectively. The contribution rates of the three industries to GDP growth were $4.8 \%, 47.4 \%$, and $47.8 \%$, respectively. The development of scientific and technological innovation is closely related to the industrial structure. The appropriate industrial structure plays a significant supporting role in promoting scientific and technological innovation. Especially the tertiary industry such as IT and financial industry is the foundation of scientific and technological innovation, and it has a great impetus to the development of scientific and technological innovation. Although Jiangxi's overall economic strength and industrial structure are increasing and optimizing, its supporting role for scientific and technological innovation is not obvious, and a 
good environment for scientific and technological innovation has not yet been formed.

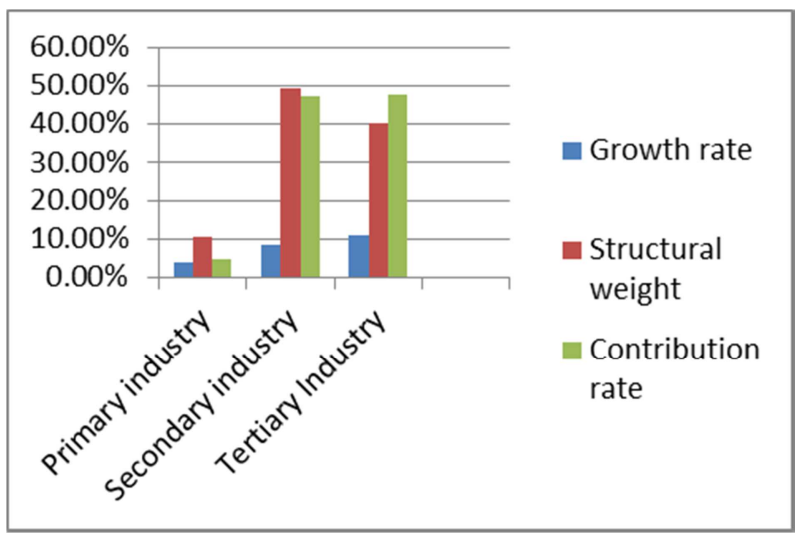

Figure 1. Relevant ratio of three industries in Jiangxi province.

\subsection{The Total Number of Carriers of Scientific and Technological Innovation Is Small, and the Service Level of the Platform Is Low}

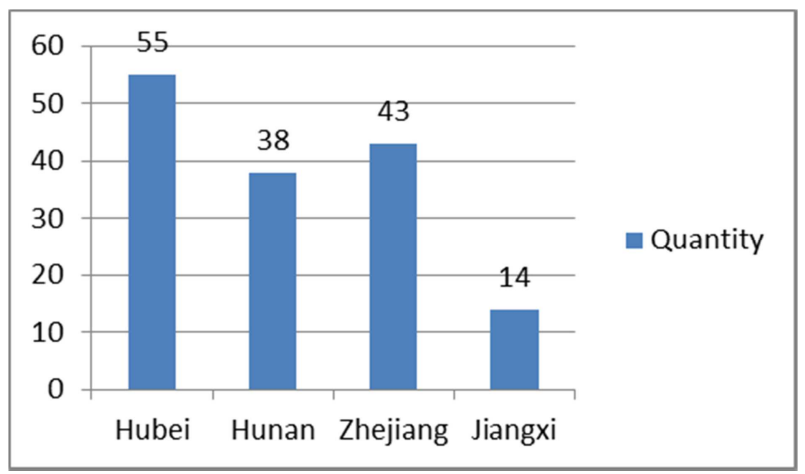

Figure 2. Number of national key laboratories and research centers.

After the guidance and support of the national policy, the construction of the Jiangxi Science and Technology Innovation Service Platform has also been fully launched. According to the survey statistics, as of 2016, Jiangxi Province has 14 national key laboratories and research centers, most of which are 14 Established after 2010, compared with the nearby provinces, such as 38 in Hunan, 55 in Hubei, and 43 in Zhejiang, the total number of scientific and technological innovation carriers in Jiangxi Province is relatively small, and the gap is large (as shown in Figure 2). As an important carrier of regional scientific and technological innovation activities, scientific and technological innovation service platform plays an important role in improving the level of regional scientific and technological innovation. Scientific and technological innovation service platform should not only give full play to its innovation ability, but also highlight its service function to provide necessary services for the development of scientific and technological innovation activities. According to the current situation of Jiangxi Science and Technology Innovation Service Platform, the service level of the platform is low, which is mainly manifested in the poor quality of platform-related websites, narrow coverage of websites, and unstable operation, slow response of manual services, low degree of informatization and weak service capacity.

\subsection{Platform Operation Mechanism Is Imperfect and Inefficient}

Jiangxi Science and Technology Innovation Service Platform has not yet formed a mechanism for enterprise management and market operation. First of all, the integration ability of the platform's science and technology resources is insufficient, and no sharing mechanism has been formed. Many scientific research institutions in Jiangxi have their own scientific research equipment, instruments and key laboratories, which are not Shared by the whole society, resulting in a large amount of waste of scarce scientific and technological resources [14]. Secondly, the platform operation has not established a scientific performance evaluation mechanism and lacks a scientific performance evaluation index system, so it is difficult to evaluate its operating benefits and effects, resulting in repeated construction of the platform, waste of resources and imbalance of input and output. Third, the platform lacks an effective achievement transformation mechanism. The transformation of scientific and technological achievements is an important way for the transformation of science and technology into real productivity and one of the main goals of the service platform for scientific and technological innovation. The scientific and technological achievements produced by Jiangxi Province are numerous in quantity, but the problem of low conversion rate of scientific and technological achievements is widespread. The main reason is that the information asymmetry between enterprises and universities and the platform for scientific and technological innovation services are not well-connected. The lack of information exchange between them has led to a serious disconnect between scientific research and production, the resulting scientific and technological achievements lack practicality and are difficult to adapt to market demand [15].

\subsection{Insufficient Platform Support, Lack of Funds and High-level Innovative Talent Input}

As an intermediary service organization, science and technology innovation service platform has strong public welfare and service characteristics. It provides efficient service for science and technology innovation activities, and needs a lot of funds and talents as support. Moreover, a large number of precision instruments are often needed for high-tech research, and these precision instruments are often expensive. Therefore, the lack of funds has become one of the important obstacles to the improvement of service level of science and technology innovation service platform. According to data monitoring, the investment in science and technology innovation activities in Jiangxi Province has been below the national average since 2008-2017 (as shown in Figure 3), and the gap is very large. In addition, talents are also an important factor restricting the platform for technological innovation services. As Jiangxi Province is in an underdeveloped region, the number of colleges and 
universities is relatively small. There is only one key university, lacking top talents and insufficient innovation ability. Therefore, insufficient capital investment and lack of talents are the main obstacles restricting the development of Jiangxi's science and technology innovation service platform.

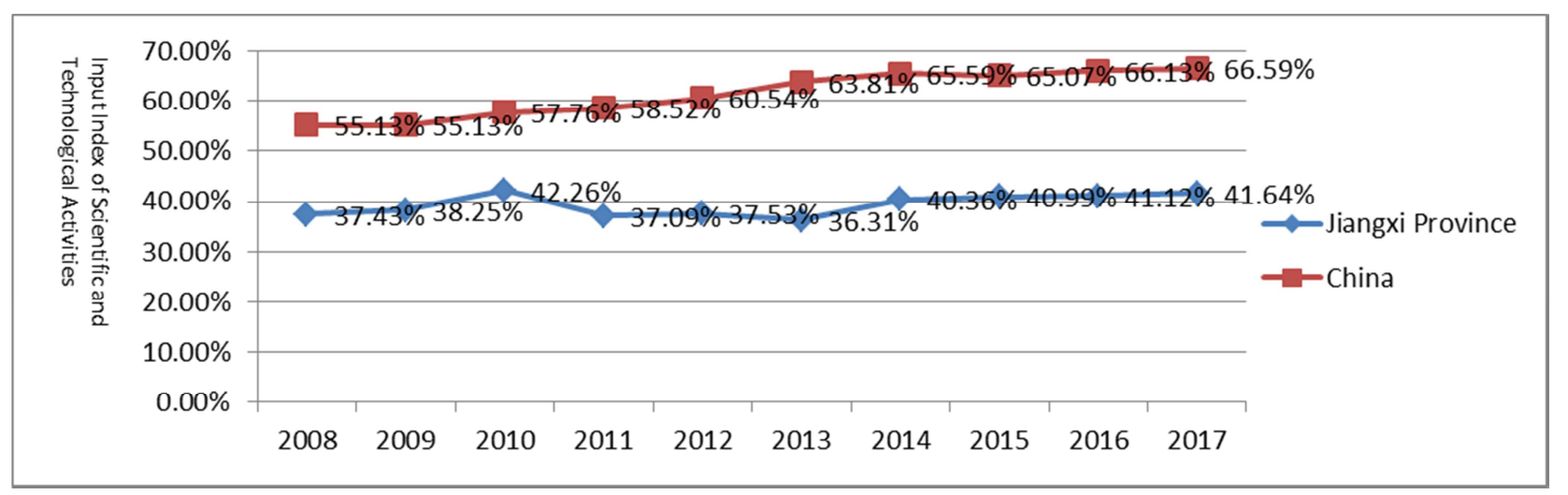

Figure 3. Contrast between Jiangxi province's investment in science and technology activities and the national average level.

\subsection{Lagging of Supporting Policies and Measures for Scientific and Technological Innovation Services}

Although Jiangxi Province has issued a series of support policies to promote technological innovation, there is no special planning and implementation opinions for the construction of science and technology innovation service platforms. For example, the annual budget is mostly used to support the construction of technology business incubators. However, the science and technology innovation service platform identified by the relevant departments at the national, provincial and municipal levels has not yet issued a corresponding incentive subsidy policy, so that public awareness of scientific and technological innovation is not High, the enthusiasm for participating in science and technology services is not strong, most enterprises are reluctant to invest because of the uncertainty of the risk of science and technology investment, and the funding bottleneck of a considerable number of scientific and technological innovation service platforms is very prominent [16]. Moreover, due to the insufficient supply of supporting measures for relevant science and technology innovation policies, the influence of science and technology innovation service platform in regional science and technology innovation activities is low, and the ability of coordination and management of science and technology resources is weak. Because there is no relevant supporting policy to guide and regulate the scientific and technological innovation activities, so that each innovation subject is independent and refuses to share relevant scientific and technological resources, the lack of supporting policy is also one of the factors restricting the development of Jiangxi Province's scientific and technological innovation service platform. [17].

\section{Experience of Developed Countries in the Construction of S\&T Innovation Service Platform}

With the development of several scientific and technological revolutions, the development of science and technology innovation service platforms in developed countries is relatively mature, and the management and operation mechanism of the platform is relatively perfect. Its superior technological innovation environment and scientific management system ensure the high output rate of its scientific and technological achievements. The experience of successful technology innovation service platforms in developed countries is mainly reflected in the following aspects.

\subsection{Platform Operation Mode is Flexible}

In the process of development of science and technology innovation service platforms in developed countries, the platform operation mode of the United States, Germany, and Japan is not static, but is adjusted along with its research direction, research fields and research priorities. In different stages of platform development, the platform of the operation mode, management mechanism and funding sources of platforms in different countries are quite different., but for the flexibility to adapt to the regional technology innovation system and the need of scientific and technological innovation service, science and technology innovation service platform is essentially take the basic pattern of government guidance or government leading, in order to make the development of the platform and innovation service ability to keep the lasting vitality.

\subsection{Collaborative Innovation of Government-Industry-University-Research Institute}

Many developed countries pay attention to strengthening the connection and communication between the platform and the government, enterprises and universities and research institutions, and are committed to collaborative innovation with universities and research institutions to continuously enhance the innovation capability and innovation vitality of the technology innovation service platform. Based on the theory of triple helix, NIST in the United States has continuously strengthened cooperation with universities and 
scientific research institutions, and the level and scale of cooperation have been increasing and expanding. In order to enhance its innovative ability and influence, KIST in Korea has gradually increased its communication and cooperation with the world through scientific research projects. German FHG is committed to international cooperation, with research centers in the United States and representative offices in several Asian countries. Through these associations, it promotes business and cooperation worldwide, demonstrating future scientific progress and economic development. In combination, the degree of integration of government, industry, university and research and the strength of collaborative innovation are deepening. The international pattern of scientific and technological innovation with multi-cooperation, future-oriented and industry-oriented development has gradually taken shape.

\subsection{Great Government Support and Diversified Sources of Funds}

In China, the inadequacy of scientific and technological innovation ability and the low transformation rate of scientific and technological achievements are largely due to the limited funds for scientific research, which leads to the low overall scientific and technological innovation ability and the low degree of industrialization of science and technology. In developed countries, the government has played a guiding and supporting role in the establishment of platforms and the construction of cooperation networks with enterprises. It has issued many policies, regulations and plans to promote the development of platforms, and provided strong financial support. Most of the construction and R\&D funds of the US Science and Technology Innovation Service Platform are mainly from the establishment of special funds by the federal government and the joint investment of the government and enterprises. German FHG has a wide range of research funding sources, from the central and local governments, as well as from the EU Science and Technology Fund and related research and development contracts [18]. In addition to government funding, AIST in Japan also raises research funds from enterprises and individuals. Overall, each country's S\&T innovation platform construction and development is characterized by increasingly diversified sources of funding and financing methods [19] (as shown in Table 1).

Table 1. Characteristics of S\&T innovation service platform in major developed countries.

\begin{tabular}{|c|c|c|c|c|}
\hline countries & $\begin{array}{l}\text { Government } \\
\text { role }\end{array}$ & $\begin{array}{l}\text { Cooperation between } \\
\text { Government, Industry, University } \\
\text { and Research Institutions }\end{array}$ & Sources of funding & Relevant policies, plans and regulations \\
\hline America & $\begin{array}{l}\text { Government } \\
\text { guidance }\end{array}$ & $\begin{array}{l}\text { Pay attention to the participation of } \\
\text { the government, enterprises and } \\
\text { Universities }\end{array}$ & $\begin{array}{l}\text { Government-funded special funds } \\
\text { for R\&D facility construction; } \\
\text { matching investment of enterprises; } \\
\text { joint investment of government and } \\
\text { enterprises }\end{array}$ & $\begin{array}{l}\text { National Information Infrastructure; } \\
\text { Guidelines for Facilities Supervision; } \\
\text { Research Facilities Act; Guide to } \\
\text { Equipment Management }\end{array}$ \\
\hline $\begin{array}{l}\text { South } \\
\text { Korea }\end{array}$ & Government-led & $\begin{array}{l}\text { Emphasis on cooperation between } \\
\text { industry, university and research } \\
\text { institute }\end{array}$ & Relying mainly on government input & $\begin{array}{l}\text { "Basic science and technology plan of the } \\
\text { lee myung-bak government for advanced } \\
\text { and first-rate countries (2008-2012)" }\end{array}$ \\
\hline Germany & $\begin{array}{l}\text { Government } \\
\text { guidance }\end{array}$ & $\begin{array}{l}\text { Focus on cooperation between } \\
\text { research institutions, universities } \\
\text { and enterprises }\end{array}$ & $\begin{array}{l}\text { Government funding; } \\
\text { Participants'joint investment; EU } \\
\text { Science and Technology Fund }\end{array}$ & $\begin{array}{l}\text { "German high-tech strategy"; "Innovation } \\
\text { funding policy and measures of the federal } \\
\text { government of Germany" }\end{array}$ \\
\hline
\end{tabular}

\subsection{Pay Attention to the Construction of Platform Performance Evaluation Mechanism}

In developed countries, the input and output efficiency of science and technology is emphasized. While building a perfect platform operation mechanism, the construction of platform performance evaluation mechanism is also emphasized to improve the overall operation level and technological innovation capability of the service platform of science and technology innovation. The National Science Foundation has developed the Equipment Supervision Guide, which evaluates the economic impact of internal projects or technology development from three different levels, and standardizes the internal self-discipline and social supervision assessment mechanisms, and accepts the federal government assessment. At the same time, other laboratories were commissioned for peer review. Japan's AIST is an independent administrative legal entity with a high degree of self-management, which adopts the enterprise-oriented management method and operates in accordance with the enterprise's management mode. Germany's FHG strengthens the performance evaluation of research institutions and associations by signing agreements with the government to ensure the quality of scientific research. Through a series of policy measures and funding plans, the technological innovation service platforms in developed countries have achieved rapid development. The main reason is that they have successfully established a "government-industry-university-research" collaborative innovation operation mode, which is the key to the successful operation of the platform. In scientific and technological innovation activities, governments, industries, universities and research institutes perform their duties and cooperate with each other, forming a perfect scientific and technological 
innovation system, which promotes the overall scientific and technological strength of developed countries.

\section{Collaborative Innovation: Development Path of Jiangxi S\&T Innovation Service Platform}

Under the environment of accelerated integration of science and technology, industry and economy, the leading role of science and technology in economic development is becoming more and more obvious. Jiangxi Province must seize the opportunity of development, strengthen the construction of innovation environment, accelerate the implementation of innovation-driven development strategy and innovation-driven "5511 Project" and build a regional innovation system with Jiangxi characteristics [20]. As far as the current environment of scientific and technological innovation in Jiangxi Province is concerned, it is necessary to build a number of scientific and technological innovation service platforms with reasonable hierarchical structure and complete functions to provide strong support for the formation of a benign mechanism of scientific and technological industrialization in the service system of scientific and technological innovation in Jiangxi Province.

\subsection{Strengthening Policy Support and Perfecting Supporting Guarantee Mechanisms}

Jiangxi Province should respond to national policy adjustments, accelerate institutional reform and management system innovation, and optimize the environment for scientific and technological innovation in Jiangxi Province. Jiangxi Province should respond to national policy adjustments, accelerate institutional reform and management system innovation, optimize Jiangxi's science and technology innovation environment, coordinate science and technology funds, optimize the structure of financial science and technology funds, enhance the support of incubators such as the creation space, and implement provincial-level technology-based business incubators. Supporting subsidy policies, implementing preferential policies in taxation, office space, electricity and network, and increasing incentives for scientific research achievements, building an inclusive policy system to support the development of science and technology innovation platforms, and increasing policy support for new research institutions [21]. At the same time, universities, research institutes and enterprises should be encouraged and promoted to form a community of interests. Government, industry, University and research institutes should jointly set up key laboratories, research workstations and industrial scientific and technological innovation alliances, devote themselves to the research and development of key projects and key technologies, form a mechanism of synergistic innovation between industry, University and research institutes, and give full play to the important media role of scientific and technological innovation service platform in social innovation activities.

\subsection{Information Resources Should Be Jointly Built and Shared to Promote Collaborative Innovation Between Industry, Universities and Research Institutes}

Establishing a sound information resource sharing mechanism is an important prerequisite and key for the science and technology innovation service platform to play its role. At present, Jiangxi Province has not established a mature information base of Industry-University-Research cooperation. There are many barriers to information sources when innovators carry out scientific and technological innovation activities. Due to insufficient information sharing and poor interaction, the stickiness of scientific research institutions and enterprises is insufficient and the phenomenon of "information isolated island" is formed, which largely restricts the ability of social scientific and technological innovation. Therefore, first of all, we should enhance the awareness of opening and sharing of scientific and technological resources, strengthen the exchange and cooperation between the platform and domestic and international scientific research institutions, adhere to the combination of "going out" and "introducing", promote enterprises to actively integrate into the global scientific and technological innovation network, and absorb and draw lessons from advanced technology and management experience at home and abroad [22]; Secondly, build a province's scientific and technological information and scientific equipment network database platform to provide open sharing services to the society. Strengthen information exchange and cooperation with enterprises, understand the trends of social demand timely, and promote the industrialization of scientific and technological achievements.

\subsection{Strengthen the Construction of Talent Team and Establish a Talent Support Mechanism}

Scientific and technological talents are the core of scientific and technological innovation activities. The competition of science and technology is the competition of scientific and technological talents. Therefore, it is necessary to strengthen the understanding that talents are the first resource, the first power and the first competitiveness. Jiangxi Province is located in the central part of China, and the teaching conditions are backward. There is only one "211 Project" university in the province, and the scientific and technological talents are relatively scarce. To introduce talents, it is necessary to create a favorable environment for talent gathering, improve the talent management mechanism, and attract domestic first-class universities to set up R\&D branches in Jiangxi [23]. Secondly, we should strengthen policy guarantee and establish and improve talent incentive mechanism. We should not only increase the number of talents, but also activate the talent stock to ensure the vitality and persistence of scientific and technological innovation of the platform. Thirdly, while introducing high-level talents, we should also strengthen the cultivation of innovative talents and the construction of innovative teams, vigorously promote the industry-university-research personnel training plan, and 
jointly train innovative teams, so as to promote breakthroughs in key core technologies and independent intellectual property rights in our province.

\subsection{Establish a Scientific Platform Evaluation Mechanism and Improve the Platform Evaluation System}

Jiangxi Science and Technology Innovation Service Platform always has the phenomenon of "attaching importance to construction and neglecting management", which leads to many problems such as decentralized investment in scientific research facilities, repeated construction, low utilization efficiency of scientific and technological resources, and low degree of sharing of scientific and technological resources [24], It is imperative to establish a scientific assessment mechanism. The nature of S\&T innovation service platform is quite unique. It has the service nature of the public sector and the competitiveness of the private sector. Therefore, its nature should be considered comprehensively in the establishment of performance appraisal system. We can use the relevant research of scholars in the performance evaluation of S\&T innovation service platform from the angles of resource integration, input and output, innovative service, operation management and social benefits. Establish a scientific performance evaluation index system and an effective evaluation mechanism. In addition, the platform performance is managed dynamically, the evaluation results are divided into different levels, and different rewards and compensation policies are adopted for different levels of platforms, so as to improve the competitiveness and innovation vitality of the platform.

\section{Conclusion}

The construction of service platform for scientific and technological innovation is a long-term and complex system engineering, which involves various subjects and levels such as politics, production, education, research, finance and innovation. Cooperative innovation is the main trend of current and future development. We must adhere to market-oriented, constantly improve the platform construction around market demand, and realize the sharing and complementarity of resources. This paper analyzes the problems existing in the construction process of China's science and technology innovation service platform by taking Jiangxi Province of China as an example. It also reflects that there is still much room for improvement in the construction of China's science and technology innovation service platform. Through on-the-spot investigation and research and analysis, the paper also puts forward pertinent countermeasures and suggestions on these issues from various aspects, promotes the implementation of relevant policies and the promulgation of new policies, so as to continuously improve the service level and operational efficiency of the service platform for scientific and technological innovation, speed up the construction and development of the platform, and enhance the level of regional scientific and technological innovation and technological competitiveness. At the same time, it is necessary to introduce new technologies such as big data and cloud computing to improve the efficiency of scientific and technological innovation and the transformation rate of scientific and technological achievements, constantly improve the operation mode and mechanism of the platform, promote the collaborative innovation of government, industry, University and research, and form a long-term service mechanism of scientific and technological collaborative innovation. By strengthening the construction of service platform for scientific and technological innovation, it will certainly play an important role in China's future economic transformation and industrial structure upgrading, promote the deep integration of China's resource chain, industry chain and innovation chain, and enhance China's scientific and technological innovation capacity, strength and influence.

\section{Acknowledgements}

This thesis is supported by the Science and Technology Research Project of Jiangxi Education Department:" Research on Performance Evaluation of Jiangxi Science and Technology Innovation Public Service Platform" (No. GJ180253).

\section{References}

[1] PARKHE A. Strategic alliance structuring: a game theoretic and transaction cost examination of interfirrm cooperation [J]. Academy of Management Journal, 1993, 36 (4): 794-829.

[2] Li Keqiang. Premier Li Keqiang made important instructions on the cooperation conference of industry, university and research cooperation. Focused on building a platform for collaborative innovation. Promoting scientific and technological problems and transforming achievements $[\mathrm{J}]$. China Science and Technology Industry, 2018 (01): 8.

[3] Liu Song. Policy Research on Further Promoting Scientific and Technological Innovation of Higher Education Service in Ordos City [J]. Scientific Management Research, 2017, 35 (04): 68-71.

[4] Davila T, Eptein M. J, Shelton R. Making innovation work: how to manage it, measure it, and profit from it [M]. New York: Pearson Press, 2006.

[5] Sanjiv S. Gulshan. Innovation Management: Reaping the benefits of Open Platforms by assimilating internal and external innovations [J]. Procedia-Social and Behavioral Sciences, 2011 (25): 46-53.

[6] Catherine W. Kilelu, Laurens Klerkx, Cees Leeuwis. Unravelling the role of innovation platforms in supporting co-evolution of innovation: Contributions and tensions in a smallholder dairy development programme [J]. Agricultural Systems, 2013 (118): 65-77.

[7] Sun Qing, Wang Hongqi. Research on the System and Operating Mechanism of Local Science and Technology Innovation Platform [J]. China Science and Technology Forum, 2010, (03). 
[8] Wang Ruimin, Zhang Wenjun, Gao Jie. Research on the Construction and Effective Operation of Public Technology Service Platform [J]. Research Management, 2010, (06).

[9] Li Zenghui, Wang Xiuting, Yan Renyan. Research on the Construction of Technology Innovation Service Platform for China's Key Industries [J]. Science and Technology Management, 2012, (03).

[10] Li Yanping, Wu Shaotang. Research on Public Innovation Service Platform for Strategic Emerging Industries Development in Wuhan [J]. Scientific and Technological Progress and Countermeasures, 2012, (02).

[11] Huang Hong. Constructing Jiangxi Science and Technology Innovation Public Service Platform to Support Regional Science and Technology Innovation System [J]. Science and Technology Plaza, 2010 (07): 227-229.

[12] Xu Diwei, Fang Shaoliang. Thoughts on the Construction of Science and Technology Basic Condition Platform in Guangdong Province [J]. Science and Technology Management Research, 2013, 33 (07): 41-44.

[13] Wei Jiansong. The operation of Jiangxi Province Science and Technology Innovation Public Service Platform based on Balanced Scorecard [D]. Jiangxi University of Finance and Economics, 2018.

[14] Yang Zhenqing, Peng Runhua. Research on the Construction of Guangxi Science and Technology Innovation Public Service Platform [J]. Market Forum, 2010 (03): 6-8.

[15] Xu Bin. Status Quo, Problems Analysis and Countermeasures of the Transformation of Scientific and Technological Achievements in Universities in Jiangxi Province [J]. Examination Weekly, 2012, (65), 150-151.
[16] Shi Jiachun. The Status Quo and Development Countermeasures of Science and Technology Innovation Service Platform in Qujing City $[\mathrm{J}]$. Innovation and Technology, 2015, 11, 25-26.

[17] ZHU Zi-Li. Research on the Construction of Public Science and Technology Service Platform in the West of Guangxi Province [J]. Journal of Hunan Finance and Economics Institute, 2015, 04 (31), 43.

[18] Ma Jizhou, Chen Zhanyun. Application Research of Fraunhofer Model in Germany-A Financing Arrangement of Industry, University and Research Institute [J]. Science of Science and Technology Management, 2005 (06): 53-55+86.

[19] Zeng Kun. Overview of the Experience of Foreign Science and Technology Innovation Platform Construction [J]. China Industrial Review, 2017 (12): 68-72.

[20] Strive for a new way of coordinated development of ecology and economy [J]. Contemporary Jiangxi, 2017 (09): 17-20.

[21] Ren Yuanyuan. Analysis of the present situation and Countermeasures of the construction of scientific and technological innovation platform in Anhui Province [J]. Economic Research Guide, 2018 (07): 71-73+80.

[22] Deng Chunxi, Chen Enlun. Actively build a collaborative innovation platform [N]. Guangming Daily, 2013-01-28 (007).

[23] Lu Xiaoyao. Theory, Practice and Countermeasure of the Construction of Science and Technology Innovation Platform [J]. Management Observation, 2017 (14): 80-81+84.

[24] Lan Wenyan. Performance Evaluation of Zhejiang Public Science and Technology Innovation Service Platform [D]. Zhejiang University of Technology, 2009. 